\title{
Brief Communication: The use of an unmanned aerial vehicle in a rockfall emergency scenario
}

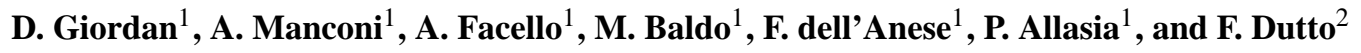 \\ ${ }^{1}$ National Research Council, Research Institute for Geo-hydrological Protection, Geohazard Monitoring Group, \\ Strada delle Cacce 73, 10135 Turin, Italy \\ ${ }^{2}$ Torino Province, Civil Protection Service, Via Alberto Sordi 13, 10095 Grugliasco, Italy \\ Correspondence to: D. Giordan (daniele.giordan@irpi.cnr.it)
}

Received: 19 May 2014 - Published in Nat. Hazards Earth Syst. Sci. Discuss.: 5 June 2014

Revised: - - Accepted: 25 December 2014 - Published: 28 January 2015

\begin{abstract}
In recent years, the use of unmanned aerial vehicles (UAVs) in civilian/commercial contexts are becoming increasingly common, as well as for applications concerning anthropic and natural disasters. In this paper, we present the first results of a research project aimed at defining a possible methodology for the use of micro-UAVs in emergency scenarios relevant to rockfall phenomena. To develop and support the method presented herein, the results relevant to a rockfall emergency occurred on 7 March 2014 in the San Germano municipality (north-western Italy) are presented and discussed.
\end{abstract}

\section{Introduction}

In mountainous regions, transportation corridors are often susceptible to landslides (Michoud et al., 2012). In particular, rock falls constitute a major hazard in numerous rock cuts. Generally, rock falls sizes ranges from small (less than a cubic metre) to large boulders (hundreds of cubic metres), and travel at speeds ranging from a few to tens of metres per second (Cruden and Varnes, 1996). Emergencies related to rock falls occurring on settlements or roads require an a priori detailed characterization of the unstable areas, as well as of their potential evolution over time. The latter areas, however, are often difficult to access due to their typical morphology. Moreover, during emergency scenarios field operations are prevented due to the potential risk associated to further gravitational phenomena. Therefore, there is a real need of straightforward procedures allowing to obtain robust and re- liable data sets in a rapid and safe manner, aiming at a achieving a more quantitative analysis of the rock mass.

In recent years, the use of unmanned aerial vehicles (UAVs) in operations relevant to civilian/commercial contexts is becoming increasingly common (Chiabrando et al., 2013). For example, an important application domain is in the area of emergency assistance and management, with scenarios including anthropic and/or natural disasters such as floods, earthquakes, and landslides (Tien-Yin et al., 2010). Micro-UAVs are used to carry lightweight instruments, such as consumer digital cameras, to acquire photographs of the area of interest and eventually allow for photogrammetric processing (Neitzel et al., 2011). Moreover, micro-UAVs are also used as a test bed for the integration of multiple instruments, as well as for the development of new sensors (Colomina, 2007).

As an example of an application in a real-case scenario, after Hurricane Katrina micro-UAVs equipped with three different sensors (pan-tilt thermal and visual sensors, and a fixed visual sensor for pilot view) were used to inspect collapsed buildings (Pratt et al., 2009). In addition, images from a micro-UAVs and unmanned sea-surface vehicles were used for inspection of bridges and seawalls for structural damages (Murphy et al., 2008). Also, after the earthquake in L'Aquila, April 2009, UAVs equipped with cameras were used for building inspection and situation assessment (Nardi, 2009).

In this paper, we present the first results of a research project aimed at defining straightforward methodologies to use micro-UAVs in emergency scenarios relevant to rockfall phenomena. The project was carried out by the Geohaz- 

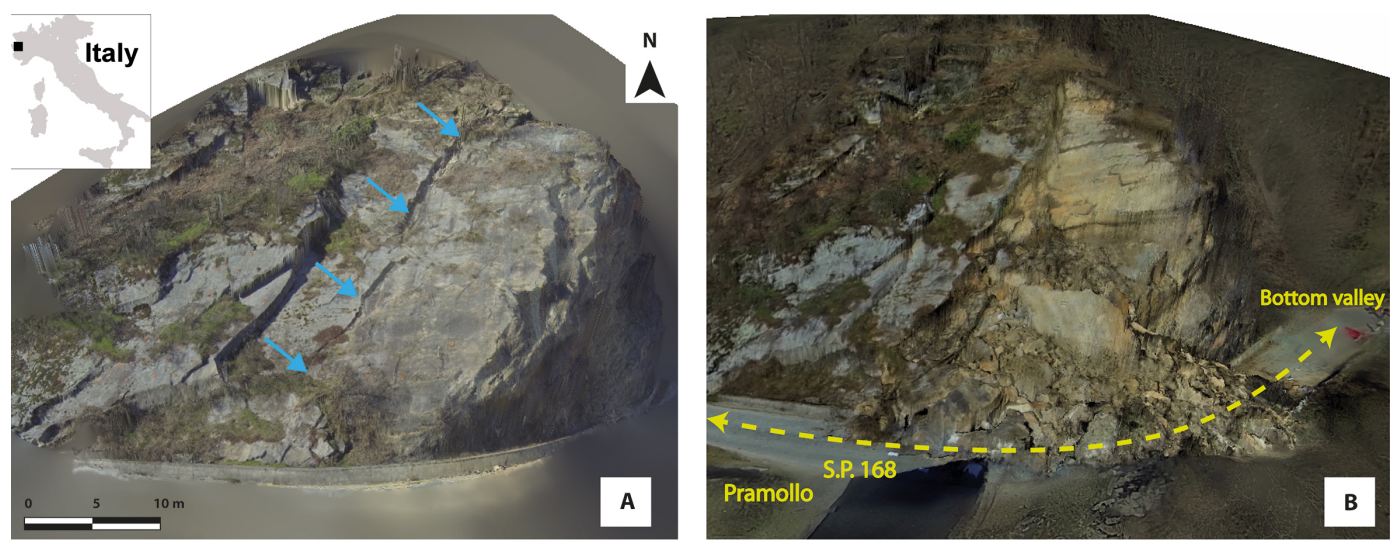

Figure 1. Comparison between 3-dimensional solid images of the study area before (a) and after (b) the San Germano rockfall event. Blue arrows indicate the main lateral fracture. Yellow dashed line indicates the road path.

ard Monitoring Group (GMG) of CNR IRPI and the Civil Protection Service of the Torino Province. The main purpose of the project is to use micro-UAVs equipped with high-resolution digital video- and photo-cameras to build up, in a rapid and straightforward manner, orthorectified 3dimensional terrain models in areas potentially affected by rockfall. In general, the expected output of the survey is a 3-dimensional solid image of the area of investigation that can be used to measure 3-dimensional coordinates from a simplified 2-dimensional visualisation. The concept of solid images was firstly introduced in 2003 as a geomatic product to describe 3-dimensional objects in a straightforward and complete manner (Bornaz and Dequal, 2004; GonzálezAguilera, 2009). In rockfall scenarios solid images can be used for the recognition and the characterization the most unstable sectors, and to support the management of emergencies. In the following, we present the first results obtained on a recent rockfall event that occurred in the San Germano municipality, northwestern Italy. There, we applied the herein presented methodology to retrieve solid images from pictures acquired by a micro-UAV during the emergency phases.

\section{The San Germano rockfall event}

At the beginning of March 2014, a critical instability involving a large portion of a rock wall was detected along the Provincial road SP 168 (Torino province, NW of Italy, see Fig. 1). The SP 168 is the sole route connecting the Pramollo municipality with the bottom of the valley, and allowing the population to reach services, schools, and workplaces. The instability involved an outcrop mainly composed of Dora Maira mica schist (Borghi et al., 1985) about $100 \mathrm{~m}$ long and $40 \mathrm{~m}$ high. Despite stabilization works that were performed about 20 years before, a large fracture progressively developed along the entire rock wall. On 6 March 2014, this fracture started opening with a rate estimated at several centimetres per day, and minor falls started to affect the rock wall. In order to comply with these clear signs of criticality, the pathway adjacent to the rock wall had been closed to traffic by the authorities responsible for the viability (Viability Service of the Torino Province, VSTP). In addition, VSTP informed the Torino Province Civil Protection Service (CPS) about the hazard potential related to the San Germano rock mass.

In this scenario, GMG and CPS operated the first survey during the afternoon of 7 March 2014. GMG performed a preliminary field observation aimed at identifying the unstable area and recognize the main evidences of activity. The principal indication of the instability was the presence of a large fracture on the frontal side of the rock wall, and the presence of trenches in the upper part of the slope over the steeper sector. The lateral side of the rock wall was suffering an increasing number of minor rock falls, and the evolution of the opening of the main fracture started to be extremely evident. The frequency of minor falls increased during the afternoon, and at 17:00 CET the road was totally closed to the traffic. At 17:15 CET the rock cliff collapsed, and more than $1 \times 10^{3} \mathrm{~m}^{3}$ of rock deposits covered the entire road path. After the collapse, the communication with the upper part of the valley and the Pramollo municipality was interrupted, and an emergency procedure to restore the street and to assure an emergency communication and support to the population was immediately settled on. The SP168 remained closed until 15 March 2014, to allow the removal of the rockfall deposits, as well as to stabilize the new profile of the rock wall modified by the event.

\subsection{Use of micro-UAVs during the San Germano emergency}

During the MASSA Project (Lanteri et al., 2015), the GMG and CPS developed a protocol to support survey activities relevant to rockfall events in order to provide decision makers with quantitative data useful for dealing with emergencies scenarios. In this context, GMG and CPS have postulated also to use of micro-UAVs equipped with digital video- 
Table 1. Summary of the data and results obtained for the San Germano case study.

\begin{tabular}{|c|c|c|c|c|c|c|}
\hline & $\begin{array}{l}\text { Date of } \\
\text { acquisition }\end{array}$ & $\begin{array}{l}\text { Type of } \\
\text { survey }\end{array}$ & Raw data & $\begin{array}{c}\text { Georeferenced } \\
\text { data }\end{array}$ & $\begin{array}{l}\text { Data set FL } \\
\text { employment }\end{array}$ & $\begin{array}{l}\text { Average ground } \\
\text { resolution }\end{array}$ \\
\hline${ }^{\circledR}$ GoPro video & 7-8 March 2014 & $\mathrm{D}$ & $\begin{array}{l}204 \\
2 \text { Mpix }\end{array}$ & No & $\begin{array}{l}\text { Generation of } \\
\text { solid image } \\
\text { and DSM }\end{array}$ & $3.5 \mathrm{~cm} \mathrm{pix}^{-1}$ \\
\hline${ }^{\circledR}$ GoPro photo & 7-8 March 2014 & $\mathrm{D}$ & $\begin{array}{l}70 \\
10 \text { Mpix }\end{array}$ & No & $\begin{array}{l}\text { Generation of } \\
\text { solid image } \\
\text { and DSM }\end{array}$ & $1 \mathrm{~cm} \mathrm{pix}^{-1}$ \\
\hline${ }^{(C)}$ Nikon AW 100 & 7 March 2014 & $\mathrm{~T}$ & $\begin{array}{l}40 \\
16 \text { Mpix }\end{array}$ & Yes & $\begin{array}{l}\text { Generation of } \\
\text { solid image } \\
\text { and DSM }\end{array}$ & $2.5 \mathrm{~cm} \mathrm{pix}^{-1}$ \\
\hline TLS survey & 11 March 2014 & $\mathrm{~T}$ & $\begin{array}{l}24 \text { million } \\
\text { points }\end{array}$ & Yes & $\begin{array}{l}\text { DTM } \\
\text { Generation }\end{array}$ & - \\
\hline $\begin{array}{l}\text { Station survey } \\
\text { reflector-less total }\end{array}$ & 11 March 2014 & $\mathrm{~T}$ & 10 points & Yes & $\begin{array}{l}\text { GCPs for } \\
\text { georeferencing }\end{array}$ & - \\
\hline
\end{tabular}

and photo-cameras to obtain a complete survey of the unstable rock mass.

According to the MASSA Project indications, a first survey with a micro-UAV has been performed on Friday 7 March 2014, shortly before the San Germano rockfall event. Moreover, a second survey has been repeated on Saturday 8 March 2014. In the event's aftermath, several complementary investigations have been performed, including terrestrial photographic surveys $\left({ }^{\circ}\right.$ Nikon AW 100) as well as a Terrestrial Laser Scanner (TLS) acquisition. The microUAV available was a six-rotor multicopter Carnboncore 950 equipped with a ${ }^{\odot}$ GoPro Hero 3 digital video-camera (hereafter referred to as ${ }^{\circledR}$ GoPro). The remote control ensured the management of the flight of the micro-UAV and of the gimbal orientation. The ground control station was equipped with a monitor displaying in streaming the data flow acquired by the ${ }^{\circ}$ GoPro. In this modality, the survey operation was performed by a team composed of the pilot, taking care of the UAVs stability only, and a geologist, monitoring in real-time the position and the point of view, and eventually indicating changes of trajectory. In these scenarios, due to the complexity of the operations and the morphological characteristics of the area investigated, the autopilot solution was not envisaged. Table 1 summarizes the data set collected during several surveys and the different settings and instruments.

The data acquired during the micro-UAV surveys have been processed with the ${ }^{\circledR}$ Agisoft Photoscan software (hereafter referred to as Photoscan). Photoscan is based on the "Structure from Motion" technique, and is capable of processing the digital images and extracting point clouds relevant to the common areas of the scenes acquired (Westoby et al., 2012). To automatically obtain the image sequence of interest also from the ${ }^{\circledR}$ GoPro videos, the MPEG2 original video was processed by means of an OpenSource video editing application, ${ }^{\odot}$ VirtualDub (v1.10.4 stable, http://www. virtualdub.org). After the selection of the suitable content, the video frame rate was downgraded to $0.20 \mathrm{fps}$ and finally exported as an image sequence (JPEG, full quality).

We generated two solid images by considering the data acquired with ${ }^{\odot}$ GoPro. Further, an additional solid image was created by using the data collected via a Nikon AW 100 data set, in order to compare the results obtained by using the micro-UAVs for terrestrial acquisitions. In total, a data set of about 200 pictures has been processed for the generation of pre- and post-event solid images. In Table 2, we present a synthetic comparison of results obtained.

The 3-dimensional solid images obtained have been used to generate a rough scale digital surface model (DSM), which can supply information about the relative dimensions of different elements inside the scene (e.g. height of the unstable area, length of the fractures). By using ground control points (GCP), it is also possible to improve the accuracy of the geographic positioning of the solid image, which can thus supply the orientations of the main discontinuities identified in the rock mass. Figure 2 shows an example of the shaded relief derived from the DSM obtained from the pre rockfall survey. This class of results can be used to perform first order quantitative analyses of the unstable volume, as well as detection of joints and their classification.

\section{Progressive results obtained by micro-UAVs in rockfall scenarios}

The San Germano case study can be considered as a test bed for the use of micro-UAVs to set up standards for rockfall 
Table 2. Comparison between the results obtained for the San Germano case study.

\begin{tabular}{|c|c|c|}
\hline data set & Advantages & Disadvantages \\
\hline $\begin{array}{l}{ }^{(C)} \text { GoPro } \\
\text { (video) }\end{array}$ & $\begin{array}{l}\text { The number of available images taken from the video is very } \\
\text { high and allows the restitution of a complete solid image of } \\
\text { the area. } \\
\text { The use of micro-UAVs allows the acquisition of images from } \\
\text { different points of view. }\end{array}$ & $\begin{array}{l}\text { The resolution of the images is low and this limitation can } \\
\text { be a problem for the representation of solid image details. } \\
\text { The lack of GPS positions does not allow to generate a } \\
\text { georeferenced solid image without the use of ground con- } \\
\text { trol points. }\end{array}$ \\
\hline $\begin{array}{l}{ }^{(C)} \text { GoPro } \\
\text { (photos) }\end{array}$ & $\begin{array}{l}\text { The number of available images taken from }{ }^{\odot} \text { GoPro is very } \\
\text { high and allows the creation of a complete solid image of the } \\
\text { area. } \\
\text { Compared with the frames extracted from videos, the } \\
\text { resolution allows the restitution of a more detailed solid } \\
\text { image. }\end{array}$ & $\begin{array}{l}\text { The lack of GPS positions does not allow to generate a } \\
\text { georeferenced solid image without the use of ground } \\
\text { control points. }\end{array}$ \\
\hline $\begin{array}{l}{ }^{(C)} \text { Nikon AW } \\
100\end{array}$ & $\begin{array}{l}\text { The high resolution of the photos and the GPS positions } \\
\text { allow for the restitution of a georeferenced high resolution } \\
\text { solid image. }\end{array}$ & $\begin{array}{l}\text { Several sectors are not covered by the solid image because } \\
\text { of shadowing. }\end{array}$ \\
\hline
\end{tabular}

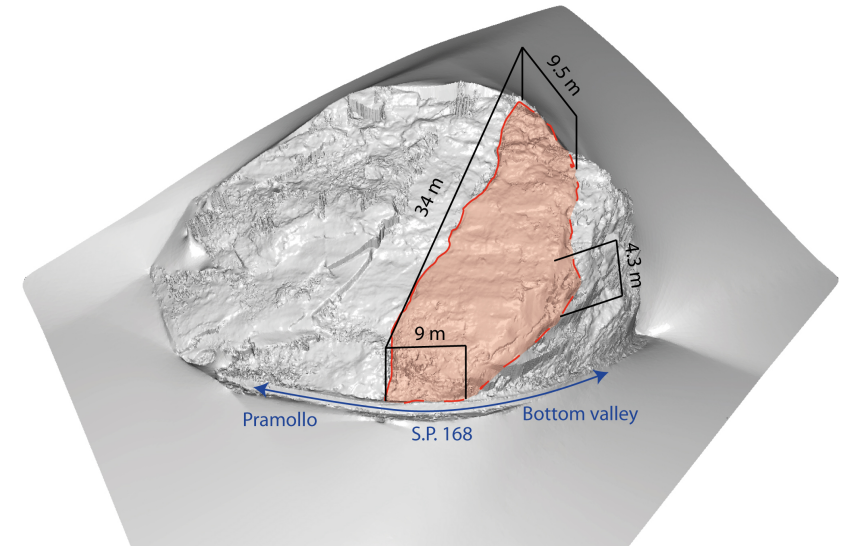

Figure 2. Shaded relief of the studied area with the indication of the dimension of the unstable sector (red area). The DSM of the unstable area before the rockfall event derived from the ${ }^{\circledR} \mathrm{GoPro}$ data set allows us to define the orientation of the main discontinuities: the principal shear plane has an orientation of 178/45 (dip direction/dip) and the lateral one of 325/81 (dip direction/dip). The maximum opening of the main fracture (continuous line on the picture) is $83 \mathrm{~cm}$. These results have been obtained in ca. $3 \mathrm{~h}$ processing time with ${ }^{\circledR}$ Agisoft Photoscan, by considering an AMD Phenom X4 $955 \mathrm{CPU}$ (3.2 GHz), $10 \mathrm{~GB}$ RAM.

emergency conditions. During emergencies, the processing time required to obtain the results is a very important element that has to be carefully considered. Time-consuming processes have the advantage of providing highly accurate results, but they are not suitable in emergency situations, where the rapidity of the response is crucial. Accordingly, we propose a procedure for the employment of micro-UAVs in rockfall scenarios consisting in several steps, which mainly depend on the processing time required to obtain the results and on their accuracy in terms of geo-positioning. The pro- cedure considers the mission planning of a micro-UAV and, in particular, the sequence of obtainable products that can be used to study the bedrock structures and instabilities.

After the micro-UAV landing and the download of the acquired digital images, three different levels of results can be obtained in a timely progressive fashion:

i. Video and photos of the unstable area: these results are immediately available on site without any post processing activity. The immediate availability of videos of the area can be a very useful support in the field, mainly because the analysis of this data allows us to image the unstable area from different points of view, unlikely to be obtainable with field surveys. In addition, aerial photos taken from the micro-UAV can be very useful; however, the picture sequences are usually not exploitable on site in a user-friendly manner. To cope with these problems, procedures of photo mosaicing can be considered to obtain a better overview of the surveyed area. At this stage, the information obtained from videos and photos is not orthorectified, thus allows only qualitative and semi-quantitative evaluations on the unstable rock mass.

ii. 3-dimensional solid images: by using dedicated software, as for example ${ }^{\odot}$ Photoscan, it is possible to extract first a point cloud relevant to the common areas acquired in the scene. Subsequently, a digital surface model (DSM) can be retrieved by calculating a best fitting surface with Delaunay triangulation or other interpolation algorithms (nearest neighbour, kriging, etc.). The combination of the DSM and the photos allows us to compose a 3-dimensional solid image of the investigated area (Hugenholtz et al., 2013; James and Robson, 2012). By considering the geographic coordinates acquired by the onboard GPS, the solid image can be 
roughly orthorectified. This second-stage result allows operators involved in the emergency scenario to have an additional tool, which can be now used for first quantitative evaluations. The resolution of the 3-dimensional solid image can be very high (in the order of 2 to $10 \mathrm{~cm}$ pixel resolution), and may allow for very detailed analyses of the structural settings of the rock mass, even in the zones with limited access. However, it is worth mentioning that most of the micro-UAVs available in the market are equipped only with L1 GPS, thus their attainable accuracy on positioning is limited (in the order of 5 to $10 \mathrm{~m}$ ). The time required to get this second-stage result depends mainly on the computing capabilities and on the size of the investigated area. In general, with offthe-shelf computers, we can consider a range of $2-3 \mathrm{~h}$ for small areas, to $10-15 \mathrm{~h}$ for larger unstable sectors.

iii. The third-stage result differs from the previous one mainly because of the level of accuracy of the 3dimensional solid image achieved through a straightforward orthorectification strategy. To increase accuracy in the geocoding, a set of ground control points (GCPs) is required. The coordinates of GCPs have to be measured by considering high accuracy geodetic instruments, such as terrestrial laser scanners, theodolites, and/or GPS receivers (Paar et al., 2012; Torrero et al., 2015). The key point is to identify a network of GCPs that have to be first recognized in the solid image, and then measure in the field their position. This kind of topographic survey can be time consuming, and increases the complexity of both the field activities and the number of people and instruments involved in the operations. In this latter case, the results are characterized by a higher accuracy in terms of orthorectification and geographic positioning, allowing for the definition of the absolute orientations of joints families (e.g. Ferrero et al., 2011), as well as permitting for a more accurate estimation of the unstable volumes. The accuracy level of these products may permit the use of the data set for monitoring purposes using a multi-temporal approach, if GCPs are stable during the investigation period.

Figure 3 describes these three different levels of output, and considers also an indication of the time necessary for the restitution of different results. We remark that the indication of necessary time depends on the dimension of the studied area and/or on the available computational capacity.

\section{Concluding remarks}

In this work, we have shown the results obtained by using micro-UAVs to survey areas affected by rockfall phenomena. In the San Germano case study, we use the micro-UAV to support the analysis of the unstable area and the evaluation of the risk with photos, videos and 3-dimensional digital

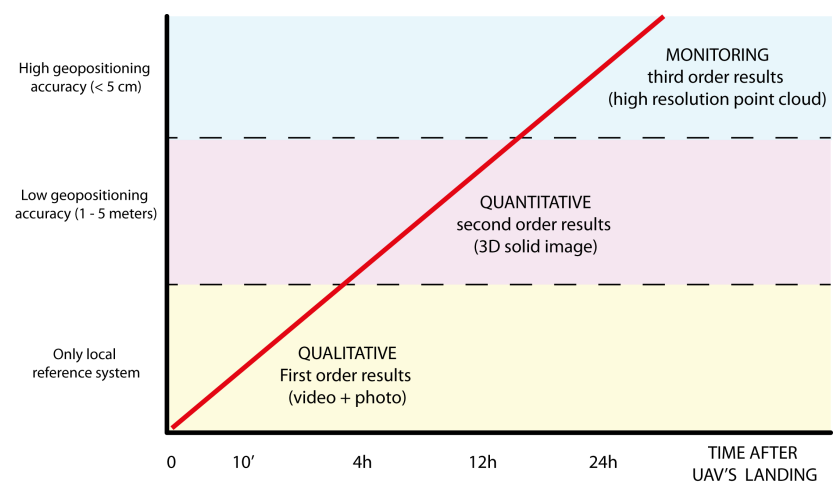

Figure 3. Schematic representation of the different results obtainable from micro-UAVs surveys in rockfall scenarios. Considering time starting after the UAV's landing, there is a direct relationship between the orthorectification accuracy level of the obtained results and the processing time. Times in the chart are indicative for a study area similar to the San Germano event, which can be considered as representative of rockfall phenomena involving the road network that can be studied through micro-UAV's surveys. The processing time is also dependent on the areal extent of the study area and computational availability.

models. The products outlined have been considered to support the CPS to manage the emergency operations. The GMG with CPS acquired a large data set using the UAV and other terrestrial instruments, mainly to cope with the emergency situation, but also to acquire know-how and possibly define a standard methodology to manage rockfall scenarios. The presented case study evidenced that the use of micro-UAVs is a suitable solution to support both qualitative and quantitative evaluations during emergency conditions, where the survey results have to be available in a rapid and straightforward manner. One of the common limitations in rockfall emergency scenarios is the availability of only limited points of view of the unstable area, which hamper a complete analysis of the detachment zone. In this context, the use of UAVs can be considered as a rapid and low cost solution to reach the zone hit by the rockfall, which is often difficult (or even impossible) to investigate in safe conditions. Indeed, micro-UAVs can be used to obtain information on the unstable area, by taking a large number of photos and videos from several points and different angles of view. According to the problems that often characterize and have to be faced in emergency conditions, we have analysed the processing time needed to get a set of results from the surveys, and defined a standard workflow for the use of micro-UAVs in rockfall scenarios. A set of products characterized by an increasing accuracy over time has also been defined to support the activities connected to the management of the emergency condition, which is the principal aim of the herein presented work. According to the processing time (Fig. 3), the qualitative results obtained are important to recognize the principal instabilities of the studied area. These are one of the most important 
elements for an appropriate evaluation of the residual risk after the first activation of a rockfall. In this way, photos and videos taken by the UAV can be used immediately on site to support the first decisions for the management of the emergency (close roads and/or evacuate houses, etc.). After the first phase, usually it is also important to have a more detailed evaluation of the unstable area to define possible scenarios. This second task needs to be supported by a quantitative approach, which allows for a first hypothesis about the unstable sectors, their position and geometry. Also in this phase, the products obtained from micro-UAVs can be considered for the analysis of the phenomenon, as well as for supporting actions of decision makers, who have the duty to manage the emergency condition, defining the elements at risk and planning a mitigation project.

In the San Germano case study, the available data set has been acquired by using a ${ }^{\odot}$ GoPro video-camera. The use of video-cameras has the main advantage of providing images of the rock mass in very different conditions. On the other hand, at the moment several limitations can be associated to the use of ${ }^{\circledR}$ GoPro: (i) videos are limited by a relatively low resolution of 2-4 Mpixel; (ii) unavailability of the geographical coordinates of the acquired images; (iii) image distortion and poor radiometric content. In our specific case, the acquisition were made from 20-30 m distance from the target, thus the limitations have been mitigated. However, by considering larger distances $(60-70 \mathrm{~m})$ the mentioned limitations may impede obtaining products suitable for rockfall analysis. Instead, photo cameras are characterized by a higher resolution (10 Mpixel and above) and radiometric content. However, the quality of the images acquired by UAVs can be hindered by problems of focusing, in particular in windy or in complex scenarios where the presence of close-up elements (like trees or others) can shadow the real target, i.e. the rock mass. In order to manage these limitations, a possible solution can be to set up a payload composed by both a video- and a photocamera, which can acquire information concurrently.

The exclusive use of micro-UAVs can be efficient for the generation of the first two order of results of the proposed methodology, but may suffer several limitations if we want to consider monitoring applications. In particular, repeatability conditions between successive surveys have to be respected. For this reason, in the San Germano case study we have contextually used a TLS acquisition to obtain a high resolution DSM of the studied area, to validate and improve the result obtained via the micro-UAVs survey. The DSM obtained via the TLS survey is characterized by a high point cloud density, and also by a very accurate geographic positioning. Indeed, two L2 GPS acquiring in static mode during the whole TLS acquisition where used to position the point cloud. The TLS has another important positive advantage: the availability of a very detailed DSM can be used to validate the results obtained via the micro-UAV (Henry et al., 2002; Jabojedoff et al., 2012). Moreover, this can also be used for a multi-temporal comparison aimed to define the morpholog- ical changes of the studied area linked to the gravitational phenomenon's evolution (Niethammer et al., 2012; Giordan et al., 2013).

In the presented case study, we also tested pros and cons associated with the use of different geodetic instruments for the acquisition of GCP, performing surveys not only with a terrestrial laser scanner (TLS) but also with a total station (TS). TS can be considered as a suitable solution to get GCP coordinates in a rapid fashion, because the post processing time is very short. Moreover, if the GCP can be well identified in the field, the measurement of their absolute position can be done using the reflector-less technique. In a time comparable to the micro-UAV survey, the TS can acquire several tens of points. The most important limitation of this approach is the a priori identification of GCP, which is usually critical because it is not always possible to also clearly recognize these points in the solid image generated by exploiting the micro-UAV survey. On the contrary, TLS is a more time consuming technique, needing more time in the field and for the data post processing. The most important added value of TLS is that it is possible to a posteriori compare the solid image and the TLS coloured point cloud and find the best matching points.

Another important limitation for the use of micro-UAVs is the occurrence of extreme weather conditions. This can be very critical, in particular during emergency condition, which usually are related to extreme weather events. However, we consider this as a current technical limitation, which will be likely solved and/or provide better performance in the near future. The use of UAV for the management of geohydrological instabilities is a new research field that will probably see a progressive increase in the next few years. The potential of these tools is very high, and their development for application is only at the beginning. At the moment, one of the most important issues is the definition of procedures for their appropriate use. Such procedures have to consider carefully both the limitations and characteristics of the UAV and the kinematic properties of the phenomenon under evaluation. In this way, the results obtained from UAVs can be well exploited in several contexts, and will improve our capability to investigate geohazards by considering this new category of remote sensing data.

Acknowledgements. We thank Andrea Bernini and Mario Truffa from the Civil Protection Service of the Torino Province for technical support during the micro-UAV survey. The comments of two anonymous referees have improved an early version of the manuscript.

Disclaimer. In this work, the use of copyright, brand, trade names and logos is for descriptive and identification purposes only, and does not imply endorsement from the authors, or their institutions. 
Edited by: O. Katz

Reviewed by: two anonymous referees

\section{References}

Borghi, A., Cadoppi, P., Porro, A., and Sacchi, R: Metamorphism in the northern part of the Dora Maira massif (Cottian Alps), Boll. Mus. Reg. Sci. Nat. Torino, 3, 369-380, 1985.

Bornaz, L., and Dequal, S.: The solid image: An easy and complete way to describe 3-D objects, Proceedings of the 20th ISPRS congress, Istanbul, Turkey, 12-23 July 2004, Volume XXXV Part B5, 183-188, 2004.

Chiabrando, F., Lingua, A., and Piras, M.: Direct Photogrammetry Using Uav: Tests And First Results, Int. Arch. Photogramm. Remote Sens. Spatial Inf. Sci., XL-1/W2, 81-86, doi:10.5194/isprsarchives-XL-1-W2-81-2013, 2013.

Colomina, I., Aigner, E., Agea, A., Pereira, M., Vitoria, T., Jarauta, R., Pascual, J., Ventura, J., Sastre, J., Brechbühler de Pinho, G., Derani, A., and Hasegawa, J.: The Uvision project for helicopter- UAV photogrammetry and remote-sensing, Proceedings of the 7th International Geomatic Week, Barcelona, Spain, 20-23 Febuary 2007, 7 pp. 2007.

Cruden, D. M. and Varnes, D. J.: Landslide types and processes, in: Landslides, Investigation and Mitigation, Special Report 247, Transportation Research Board, Washington, 36-75, 1996.

Eisenbeiss, H.: The autonomous mini helicopter: a powerful platform for mobile mapping, Proceedings of the 21th ISPRS congress, Beijing, China, 3-11 July 2008, Volume XXXVII Part B1, 977-984 2008.

Ferrero, A. M., Migliazza, M., Roncella, R., and Rabbi, E.: Rock slopes risk assessment based on advanced geostructural survey techniques, Landslides, 8, 221-231, doi:10.1007/s10346-0100246-4, 2011.

Giordan, D., Allasia, P., Manconi, A., Baldo, M., Santangelo, M., Cardinali, M., Corazza, A., Albanese, V., Lollino, G., and Guzzetti, F.: Morphological and kinematic evolution of a large earthflow: The Montaguto landslide, southern Italy, Geomorphology, 187, 61-79, doi:10.1016/j.geomorph.2012.12.035, 2013.

González-Aguilera, D., Muñoz-Nieto, A., Gómez-Lahoz, J., Herrero-Pascual, J., and Gutierrez-Alonso, G.: 3-D Digital Surveying and Modelling of Cave Geometry, Application to Paleolithic Rock Art: Sensors, 9, 1108-1127, 2009.

Henry, J-B., Malet, J. P., Maquaire, O., and Grussenmeyer, P.:The use of small-format and low-altitude aerial photos for the realization of high-resolution DEMS in mountainous areas: application to the Super-Sauze earthflow (Alpes-de-Haute-Provence, France), Earth Surf. Process. Landforms 27, 1339-1350, 2002.

Hugenholtz, C. H., Whitehead, K., Brown, O. W., Barchyn, T. E., Moorman, B. J., LeClair, A., Riddell, K., and Hamilton, T.: Geomorphological mapping with a small unmanned aircraft system (sUAS): Feature detection and accuracy assessment of a photogrammetrically-derived digital terrain model, Geomorphology, 194, 16-24, 2013.

Jaboyedoff, M., Oppikofer, T., Abellan, A., Derron, M.H., Loye, A., Metzger, R., Pedrazzini, A.: Use of LIDAR in landslide investigations: a review, Nat. Hazards, 61, 5-28, doi:10.1007/s11069010-9634-2, 2012.
James, M. R. and Robson, R.: Straightforward reconstruction of 3-D surfaces and topography with a camera: Accuracy and geoscience application, J. Geophys. Res.-Earth, 117, F03017, doi:10.1029/2011JF002289, 2012.

Pratt, K., Murphy, R., Stover, S., and Griffin, C.: CONOPS and autonomy recommendations for VTOL small unmanned aerial system based on Hurricane Katrina operations, J. Field Robot., 26, 636-650, doi:10.1002/rob.20304, 2009.

Lanteri, L., Bormioli, D., Morelli, M., Dutto, F., Giordan, D., and Manconi, A.: Rockfall Analysis during Emergency Scenarios, edited by: Lollino, G. Manconi, A., Guzzetti F., Culshaw M., Bobrowsky P., Luino F., Engineering Geology for Society and Territory, Springer International Publishing, 5, 711-714. 2015.

Michoud, C., Derron, M.-H., Horton, P., Jaboyedoff, M., Baillifard, F.-J., Loye, A., Nicolet, P., Pedrazzini, A., and Queyrel, A.: Rockfall hazard and risk assessments along roads at a regional scale: example in Swiss Alps, Nat. Hazards Earth Syst. Sci., 12, 615-629, doi:10.5194/nhess-12-615-2012, 2012.

Murphy, R. R., Steimle, E., Griffin, C., Cullins, C., Hall, M., and Pratt, K.: Cooperative use of unmanned sea surface and micro aerial vehicles at Hurricane Wilma, J. Field Robot., 25, 164-180, 2008.

Nardi, D.: Intelligent systems for emergency response, Invited talk in Fourth International Workshop on Synthetic Simulation and Robotics to Mitigate Earthquake Disaster (SRMED 2009).

Neitzel, F. and Klonowski, J.: Mobile 3D Mapping With A LowCost Uav System, Int. Arch. Photogramm. Remote Sens. Spatial Inf. Sci., XXXVIII-1/C22, 39-44, doi:10.5194/isprsarchivesXXXVIII-1-C22-39-2011, 2011.

Niethammer, U., James, M. R., Rothmund, S., Travelletti, J., and Joswig, M.: UAV-based remote sensing of the Super-Sauze landslide: Evaluation and results, Eng. Geology, 128, 2-11, 2012.

Paar, G., Huber, N. B., Bauer, A., Avian, M., and Reiterer, A.: Vision-based terrestrial surface monitoring, in: Terrigenous Mass Movements, edited by: Pradhan, B. and Buchroithner, M., Springer, Heidelberg New York Dordrecht London, 283-348, doi:10.1007/978-3-642-25495-6_10, 2012.

Tien-Yin, C., Mei-Ling, Y., Ying-Chih, C., Yen-Hung, C.: Disaster monitoring and management by the unmanned aerial vehicle technology, ISPRS Technical Commission VII Symposium 100 Years ISPRS Advancing Remote Sensing Science, Vienna, Austria, 5-7 July 2010, Vol. XXXVIII, Part 7B, 137-142, 2010.

Torrero, L., Seoli, L., Molino, A., Giordan, D., Manconi, A., Allasia, P., Baldo, M.: The Use of Micro-UAV to Monitor Active Landslide Scenarios, in: Engineering Geology for Society and Territory, edited by: Lollino, G. Manconi, A., Guzzetti F., Culshaw M., Bobrowsky P., Luino F., Springer International Publishing, Heidelberg, Germany, 5, 701-704, 2015.

Westoby, M. J., Brasington, J., Glasser, N. F., Hambrey, M. J., and Reynolds, M. J.: Structure-from-Motion photogrammetry: A low-cost, effective tool for geoscience applications, Geomorphology, 179, 300-314, 2012. 